\title{
Exploitation of Agricultural Wastes and By-Products for Production of Aureobasidium pullulans Y-2311-1 Xylanase: Screening, Bioprocess Optimization and Scale Up
}

\author{
Sirma Yegin ${ }^{1} \cdot$ Ali Oguz Buyukkileci ${ }^{2} \cdot$ Sayit Sargin $^{3} \cdot$ Yekta Goksungur $^{1}$
}

Received: 26 January 2016/Accepted: 28 July 2016/Published online: 9 August 2016

(C) Springer Science+Business Media Dordrecht 2016

\begin{abstract}
The potential of several agricultural wastes and by-products (wheat bran, oat bran, corn cob, brewer's spent grain, malt sprout, artichoke stem, sugar beet pulp, olive seed, cotton stalk and hazelnut skin) was examined as the substrate for xylanase production by Aureobasidium pullulans Y-2311-1. Based on the screening studies, wheat bran was selected as the best substrate for further optimization studies. The effects of initial medium $\mathrm{pH}$, temperature and incubation time on xylanase production in shake flask system were optimized by response surface methodology (RSM). The optimum levels of the process variables defined by the model (initial medium $\mathrm{pH}, 4.24$; temperature, $30.27^{\circ} \mathrm{C}$; and incubation time $126.67 \mathrm{~h}$ ) resulted in production of $85.19 \mathrm{U} / \mathrm{ml}$ xylanase. Taking the RSM optimized parameters in shake-flask scale into consideration; xylanase production was scaled up to bioreactor system with a working volume of 1.51 . The peak of enzyme production was achieved after $126 \mathrm{~h}$ incubation that has previously been determined by RSM studies at shake flask level. Furthermore, the optimum levels of agitation and aeration in bioreactor system was found as $200 \mathrm{rpm}$ and $1.5 \mathrm{vvm}$. Maximum enzyme production was close to $85 \mathrm{kU} / \mathrm{l}$ which could be translated into a productivity of $0.68 \mathrm{kU} / \mathrm{l} / \mathrm{h}$. No previous work considered the statistical optimization of xylanase production by
\end{abstract}

Sirma Yegin

sirma.yegin@ege.edu.tr; sirma_yegin@yahoo.com

1 Department of Food Engineering, Ege University, 35100 Bornova, Izmir, Turkey

2 Department of Food Engineering, Izmir Institute of Technology, 35430 Urla, Izmir, Turkey

3 Department of Bioengineering, Ege University, 35100 Bornova, Izmir, Turkey
A. pullulans on wheat bran and scale up of the bioprocess to a bioreactor system.

Keywords By-product valorization - Xylanase · Aureobasidium pullulans . Bioprocess optimization . Bioreactor

\section{Introduction}

Pollution problems associated with accumulation of agroindustrial wastes and by-products increased the demand for bioconversion of the plant biomass to value added compounds by economically feasible ways. Bioprocesses are effective options for utilization of plant biomass for production of several industrially useful products such as enzymes, pigments, oligosaccharides and biofules etc.

Xylan is the major component of plant lignocellulosic biomass after cellulose representing approximately one third of all renewable organic carbon on the earth [1]. Xylanases (E.C. 3.2.1.8) are the principle enzymes acting on $\beta$-1,4-glycosidic bonds in xylan backbone. Industrial production of xylanases is based on microbial biosynthesis. Xylanases from microbial sources have several advantages such as: (1) high specificity, (2) mild reaction conditions requirement, (3) negligible amount of substrate loss, (4) insignificant amount of side product generation [2]. Microbial xylanases have a wide range of applications in several industrial processes. They have potential applications in mainly food, animal feed, paper and pulp industries. In food industry, xylanase are mainly used in bread making. Application of xylanases in bread formulation provides improvement of rheological properties of dough, bread specific volume, and crumb firmness [3]. Xylanase are used in clarification of must and juices together with 
pectinases and cellulases [4]. They also find applications in extraction of coffee, plant oils and starch [5]. In brewing industry, xylanase are used to improve filtration efficiency [6]. In poultry production, supplementation of xylanase in feed formulation improves both weight gain and feed conversion efficiency [4]. Xylanase preparations are also widely used in biobleaching process in paper and textile industries [7]. In addition, they are also exploited for bioconversion of lignocellulosic waste into a variety of valueadded biological compounds (e.g. xylitol, xylooligosaccharides, and surfactants).

The successful industrial application of xylanases requires their cost-effective production in bulk quantities. Xylanase production by various fungi and bacteria has been shown to be inducible [2]. However, utilization of commercially available pure xylans as the substrate and inducer in medium formulations is extremely expensive. It has been estimated that more than $30 \%$ of the total production cost of industrial enzymes is accounted by the substrate cost [8]. Therefore, cost-effective production of xylanase can partly be achieved by utilization of abundantly and cheaply available agricultural by-products and wastes as the substrate. Several studies have already been performed on utilization of agro-residues for xylanase production. For example, Katapodis et al. [9] examined the potential of different agro-residues (wheat bran, corn cob, sugar beet pulp and wheat straw) on xylanase production by Chaetomium thermophilum and wheat straw was reported as the best substrate for xylanase production. Bakir et al. [10] also tested the effect of different agro-residues on xylanase production by Rhizopus oryzae. Hazelnut shell, wheat stem, wheat straw, cotton bagasse, corn cob and, oat saw dust were used as the carbon source for enzyme production. Among those residues, corn cob was found as the best substrate for xylanase production. Kar et al. [11] utilized wheat bran, rice bran, rice straw, saw dust, coconut coir pith, dry banana leaf, tea exhaust and sugarcane baggase as the substrates for xylanase production by Trichoderma reesei. It was noted that maximum enzyme production was obtained in the presence of wheat bran. These studies have showed that the choice of appropriate substrate for xylanase production is very crucial for high level of xylanase biosynthesis. It is also important to emphasis that the substrate preference of each microorganism for xylanase production differs. Therefore, case specific studies should be carried out in order to elucidate the substrate preference of the microorganism of interest.

To date, several xylanase producing strains have been described. However, commercial xylanase production is mainly carried out by Trichoderma sp. and Aspergillus sp. [2]. The certain isolates of polymorphic fungi Aureobasidium pullulans were recognized as high level of cellulase free xylanase producers. These strains were designated as color variants [12]. The yeast like morphology of the mentioned strains compared to other fungal sources also offers an advantage for easy manipulation of bioprocess conditions. However, relevant studies related to xylanase production by Aureobasidium pullulans strains focusing on bioprocess optimization are scarce.

In the view of the above-mentioned reasons, this study was performed with the following objectives: (1) screening of ten agricultural by-products (wheat bran, oat bran, corn cob,brewer's spent grain, malt sprout, artichoke stem, sugar beet pulp, olive seed, cotton stalk and hazelnut skin) to evaluate their potential for production of xylanase by A. pullulans Y-2311-1; (2) optimization of bioprocess parameters (initial medium $\mathrm{pH}$, temperature and incubation time) affecting xylanase production in shake flask cultures by response surface methodology (RSM) using the substrate with highest potential for xylanase production; (3) scale-up of the fermentation to laboratory type stirred-tank bioreactor system with RSM-optimized parameters in order to further elucidate the effects of agitation and aeration on xylanase production.

\section{Materials and Methods}

\section{Materials}

All of the medium components were purchased from AppliChem GmbH (Darmstadt, Germany), except yeast nitrogen base which was from Difco (BD Detroit, USA). Xylan (from beechwood) was from BOC Science (Shirley, New York, USA). All other chemicals used were analytical grade and purchased from Sigma-Aldrich Chemie $\mathrm{GmbH}$ (Steinheim, Germany).

All agricultural by-products used as microbial substrates were supplied from local suppliers in Turkey. The substrates were washed thoroughly with distilled water, chopped and dried at $60^{\circ} \mathrm{C}$ in a hot air oven. The dried materials were powdered in a laboratory type hammer mill to a particle size smaller than $5 \mathrm{~mm}$. However, the substrates; wheat bran, oat bran, malt sprout and hazelnut skin were provided in powder form by the suppliers. The particle sizes of these substrates were also smaller than $5 \mathrm{~mm}$.

\section{Microorganisms and Culture Conditions}

A. pullulans NRRL Y-2311-1 used throughout this study was kindly supplied by the US Department of Agriculture, Agricultural Research Service. The strain was maintained on yeast-mold media $(\mathrm{YM})$ containing $(\mathrm{g} / \mathrm{l})$ : yeast extract 3.0, malt extract 3.0, peptone 5.0, glucose 10.0 and agar 20.0. The YM plates were incubated at $24{ }^{\circ} \mathrm{C}$ for 3 days and sub-cultured every 3 weeks. 
Cells for inoculation of the culture medium were obtained from cultures grown on YM agar plates at $24{ }^{\circ} \mathrm{C}$ for 3 days. Two loops of $A$. pullulans cells were transferred into $250 \mathrm{ml}$ Erlenmeyer flasks containing $50 \mathrm{ml}$ of culture medium ( $\mathrm{pH}$ 5.0) of the following composition ( $\mathrm{g} / \mathrm{l})$ : xylose 10.0, yeast nitrogen base, 6.7; asparagine 2.0, $\mathrm{KH}_{2} \mathrm{PO}_{4} 5.0$ [13]. The medium was sterilized at $121^{\circ} \mathrm{C}$ for $15 \mathrm{~min}$. The flasks were incubated at $28{ }^{\circ} \mathrm{C}$ for 1 day in a rotary shaker incubator at $150 \mathrm{rpm}$.

\section{Xylanase Production}

Xylanase production was performed in $250 \mathrm{ml}$ Erlenmeyer flasks containing $50 \mathrm{ml}$ nutrient medium with the following basic composition $(\mathrm{g} / \mathrm{l})$ : agricultural by-product 10.0, yeast extract 1.0, $\left(\mathrm{NH}_{4}\right)_{2} \mathrm{SO}_{4} 2.5, \mathrm{KH}_{2} \mathrm{PO}_{4}$ 5.0. The $\mathrm{pH}$ of the medium was adjusted to 3.0 with $\mathrm{HCl}$ and $\mathrm{NaOH}$. The medium was sterilized at $121{ }^{\circ} \mathrm{C}$ for $15 \mathrm{~min}$. The flasks were inoculated with $2 \%$ of the inoculum. At the end of the fermentation, the biomass and insoluble substrate were removed by centrifugation $(21,500 \times g)$ at $4{ }^{\circ} \mathrm{C}$ for $15 \mathrm{~min}$ and the supernatant was referred to crude enzyme.

\section{Experimental Design}

The results of our earlier experiments indicated that initial medium $\mathrm{pH}$, temperature and incubation time were the most significant parameters affecting xylanase production by $A$. pullulans. Therefore, these three bioprocess parameters were selected to be further optimized by RSM. Face centered central composite design was utilized to evaluate the effects of critical parameters on xylanase production. The statistical analysis of the data was performed by using Minitab 17 (Minitab Inc., State College, Pennsylvania, USA)

The boundary limits of each variable determined from the preliminary studies were listed in Table 1a. The low, middle and high level of each variable were coded as $-1,0$ and +1 , respectively. An experimental plan consisting of 20 experiments was generated by the Minitab 17 software (Table 1b). Each experiment was performed in duplicate and results were shown as mean values. The following empirical second order polynominal equation was used to define a predictive model to explain the effects of system variables on response:

$\mathrm{Y}=\beta_{0}+\beta_{1} \mathrm{X}_{1}+\beta_{2} \mathrm{X}_{2}+\beta_{3} \mathrm{X}_{3}+\beta_{11} \mathrm{X}_{1}^{2}+\beta_{22} \mathrm{X}_{2}^{2}+\beta_{33} \mathrm{X}_{3}^{2}$ $+\beta_{12} X_{1} X_{2}+\beta_{13} X_{1} X_{3}+\beta_{23} X_{2} X_{3}$

where $Y$ is the response, $X_{1}, X_{2}$ and $X_{3}$ are the factors according to Table $1 \mathrm{a}$. $\beta_{0}$ is the intercept; $\beta_{1}, \beta_{2}, \beta_{3}$ are the coefficients of linear terms; $\beta_{11}, \beta_{22}, \beta_{33}$ are the coefficients
Table 1 (a) Levels of factors used in experimental design, (b) face centered central composite design for xylanase production on wheat bran

\begin{tabular}{llcrr}
\hline a) & & & \\
\hline Independent variables & Symbol coded & \multicolumn{2}{l}{ Levels } & \\
\cline { 3 - 5 } & & \multicolumn{1}{l}{-1} & 0 & +1 \\
\hline Initial medium pH & $\mathrm{X}_{1}$ & 3 & 5 & 7 \\
Temperature $\left({ }^{\circ} \mathrm{C}\right)$ & $\mathrm{X}_{2}$ & 26 & 28 & 30 \\
Incubation time $(\mathrm{h})$ & $\mathrm{X}_{3}$ & 72 & 96 & 120
\end{tabular}

\begin{tabular}{|c|c|c|c|c|}
\hline Run & $\begin{array}{l}\text { Initial } \\
\text { medium pH }\end{array}$ & $\begin{array}{l}\text { Temperature } \\
\left({ }^{\circ} \mathrm{C}\right)\end{array}$ & $\begin{array}{l}\text { Incubation } \\
\text { time (h) }\end{array}$ & $\begin{array}{l}\text { Xylanase } \\
\text { activity (U/ml) }\end{array}$ \\
\hline 1 & 7 & 26 & 120 & 19.74 \\
\hline 2 & 5 & 28 & 96 & 77.02 \\
\hline 3 & 3 & 30 & 120 & 68.47 \\
\hline 4 & 5 & 28 & 120 & 74.74 \\
\hline 5 & 3 & 26 & 120 & 73.94 \\
\hline 6 & 5 & 28 & 96 & 76.43 \\
\hline 7 & 5 & 28 & 96 & 76.14 \\
\hline 8 & 7 & 28 & 96 & 18.47 \\
\hline 9 & 3 & 28 & 96 & 71.14 \\
\hline 10 & 5 & 28 & 96 & 76.53 \\
\hline 11 & 5 & 26 & 96 & 81.13 \\
\hline 12 & 7 & 30 & 72 & 13.97 \\
\hline 13 & 5 & 28 & 96 & 76.50 \\
\hline 14 & 7 & 30 & 120 & 14.94 \\
\hline 15 & 5 & 28 & 72 & 76.83 \\
\hline 16 & 5 & 30 & 96 & 74.14 \\
\hline 17 & 5 & 28 & 96 & 77.31 \\
\hline 18 & 3 & 30 & 72 & 64.61 \\
\hline 19 & 3 & 26 & 72 & 78.23 \\
\hline 20 & 7 & 26 & 72 & 24.38 \\
\hline
\end{tabular}

of squared terms while $\beta_{12}, \beta_{13}, \beta_{23}$ are the coefficients of interactions among the independent variables [14].

\section{Bioreactor Studies}

Taking RSM-optimized parameters into account, a BioFlo 110 Modular Benchtop Fermentor (New Brunswick Scientific Corporation, NJ, USA) with 3.01 vessel (1.5 l working volume) was used for further studying the effects of the agitation speed and aeration rate on xylanase production. The system consisted of a glass vessel with 4 equally spaced vertical baffles. Agitation was done by dual Rushton-style impellers. The production medium and the reaction vessel were sterilized at $121{ }^{\circ} \mathrm{C}$ for $20 \mathrm{~min}$. 


\section{Analytical Methods}

\section{Enzyme Assay}

Xylanase activity was determined according to Bailey et al. [15]. The assay mixture containing $0.9 \mathrm{ml}$ of $0.5 \%$ (w/v) beechwood xylan prepared in $0.05 \mathrm{M}$ citrate buffer (pH 5.2) as the substrate and $0.1 \mathrm{ml}$ of suitably diluted enzyme preparation was incubated at $50{ }^{\circ} \mathrm{C}$ for $5 \mathrm{~min}$. The reaction was terminated by the addition of $1.5 \mathrm{ml}$ 3,5-dinitro salicylic acid (DNS) reagent and the content was boiled for $5 \mathrm{~min}$ followed by cooling in ice-cold water for $1 \mathrm{~min}$. A control for each sample was run simultaneously that contained all the reagents, where the reaction was terminated prior to the addition of the enzyme. The amount of reducing sugars released in the reaction was estimated by measuring the absorbance at $540 \mathrm{~nm}$. Xylose was used as the standard. One unit of xylanase activity was defined as the amount of enzyme required to release $1 \mu \mathrm{mol}$ of xylose equivalent per min. The xylanase activity was calculated using the following formula:

Activity $(\mathrm{U} / \mathrm{ml})=(\mathrm{X} / 150.13) \times(1 / 5) \times(1 / 0.1) \times \mathrm{D}$

where $\mathrm{D}$ is dilution factor and $\mathrm{X}$ is the amount of xylose in $\mu \mathrm{g}$.

\section{Protein Determination}

Total protein was estimated according to the modified Bradford method, using a Coomassie Plus ${ }^{\mathrm{TM}}$ Protein Assay Kit (Pierce, Fischer Scientific, Schwerte, Germany). Bovine serum albumin (BSA) was utilized as the standard.

\section{Carbohydrate Determination}

Total carbohydrate was determined by employing the phenol-sulphuric acid procedure [16].

\section{Electrophoresis}

Sodium dodecyl sulfate polyacrylamide gel electrophoresis (SDS-PAGE) was performed according to Laemmli [17] using $12.5 \%$ (w/v) polyacrylamide gels. Protein bands were visualized by employing either Comassie brillant blue R250 staining or silver staining protocol [18] depending on the protein concentration of the samples.

\section{Results and Discussion}

\section{Screening of the Potential of Agricultural By- Products for Xylanase Production}

The critical factors for efficient xylanase production are the selection of a suitable inducing substrate and an optimum medium formulation [2, 19]. Even though pure xylan provides very good activity levels as a carbon source and inducer for various microorganisms, it is too expensive to be used for bulk xylanase production. Therefore, plant lignocellulosic biomass has been recognized as the potential substrate for economical production of xylanases. In the present study, the influence of several agricultural byproducts on xylanase production as the substrate was determined and the results were presented in Table 2. Maximum xylanase activity $(67.44 \pm 2.12 \mathrm{U} / \mathrm{ml})$ was obtained in presence of wheat bran. Corn cob $(62.75 \pm 2.83 \mathrm{U} / \mathrm{ml})$ and brewer's spent grain $(63.25 \pm 4.95 \mathrm{U} / \mathrm{ml})$ also provided similar activity levels. The highest specific activity was observed when corn cob was utilized (2236.28 U/mg). However, the activity levels for other agricultural by-products were less being negligible for cotton stalk and hazelnut skin. Xylan is a very complex polymer and the structure of xylan in plant biomass differs from each other. When complex substrates are used for xylanase production, several factors have joint effects on enzyme expression levels [2]. The key factors that influence the amount of xylanase production related to the type of the substrate used are; the chain length, the degree of branching and the presence of substituents in the xylan structure [20]. Studies which have been carried out by utilizing different types of pure xylans revealed that the xylanase obtained from A. pullulans Y-2311-1 prefers long chain xylans and is very effective against substituents [21]. Xylan from wheat bran is composed of a $\beta$-D-(1,4)-linked xylopyranosyl backbone and can be substituted with $\alpha$-Larabinofuranosyl as the major side group on $\mathrm{O} 2$ and/or $\mathrm{O} 3$ [22]. It also contains significant amounts of phenolic acids such as ferulic and $p$-coumaric acids which are esterified to arabinofuranosyl residues [23]. This high substitution pattern might be one of the reasons that makes wheat bran the best substrate for A. pullulans xylanase production. Wheat bran has been reported as an ideally suitable substrate for xylanase production for other microorganisms as well; such as Streptomyces sp. RCK-2010 [24], Trichoderma reesei SAF3 [11], Aspergillus awamori [25]. From another perspective, xylanases bind tightly to the substrate and consequently a part of the enzyme produced during the fermentation is often lost and discarded, as bound enzyme, along with the insoluble substrate [19]. The enzyme-substrate interactions could also be another reason for the 
Table 2 Screening the potential of agricultural byproducts for xylanase production (initial medium $\mathrm{pH}$ : 3.0, temperature: $28{ }^{\circ} \mathrm{C}$, agitation: $200 \mathrm{rpm}$, time: $96 \mathrm{~h}$ )

\begin{tabular}{lccc}
\hline Agricultural by-product & Xylanase activity $(\mathrm{U} / \mathrm{ml})$ & Total protein $(\mu \mathrm{g} / \mathrm{ml})$ & Specific activity $(\mathrm{U} / \mathrm{mg})$ \\
\hline Wheat bran & $67.44 \pm 2.12$ & $56.45 \pm 4.53$ & 1194.70 \\
Corn cob & $62.75 \pm 2.83$ & $28.06 \pm 2.10$ & 2236.28 \\
Brewer's spent grain & $63.25 \pm 4.95$ & $79.03 \pm 6.30$ & 800.33 \\
Malt sprout & $55.22 \pm 6.88$ & $150.97 \pm 16.32$ & 365.77 \\
Oat bran & $34.27 \pm 2.50$ & $60.32 \pm 3.91$ & 568.14 \\
Artichoke stem & $10.57 \pm 1.06$ & $23.23 \pm 2.83$ & 455.02 \\
Sugar beet pulp & $4.86 \pm 0.57$ & $79.97 \pm 6.28$ & 60.77 \\
Olive seed & $4.36 \pm 0.42$ & $26.90 \pm 1.85$ & 162.08 \\
Cotton stalk & $0.81 \pm 0.16$ & $12.68 \pm 3.43$ & 63.88 \\
Hazelnut skin & $0.51 \pm 0.16$ & $211.29 \pm 15.76$ & 2.41 \\
\hline
\end{tabular}

variations in enzyme production levels on different substrates. In the present study, because of providing the highest xylanase activity, wheat bran was utilized in medium formulation for further optimization studies. On the other hand, it is important to note that 15-20\% (in weight) of the wheat bran is discarded during wheat flour production process. Therefore, wheat bran can be accepted as a sustainable by-product for microbial production of several industrially important enzymes [26].

\section{SDS-PAGE Pattern of Crude A. pullulans Y-2311-1 Xylanase on Different Substrates}

The protein pattern of the crude enzyme preparations produced on different substrates was examined by SDSPAGE. It has been previously mentioned that A. pullulans Y-2311-1 produces multiple monomeric xylanases having approximately 20 and $21 \mathrm{kDa}$ molecular masses as judged by SDS-PAGE [12]. Biosynthesis of multiple xylanases by numerous microorganisms has been reported due to the heterogeneity of xylans from different sources [7].

In the present study, the agricultural by-products providing higher enzyme activity with high protein concentration have been collected in the same gel and comassie brillant blue R250 staining has been employed (Fig. 1a). However, the agricultural by-products providing low enzyme activities grouped in another gel where silver staining has been employed for visualization (Fig. 1b). As it is seen in Fig. 1a; a clear predominant protein band of approximately $20 \mathrm{kDa}$ was common for the crude enzymes produced on wheat bran, corn cob, brewer's spent grain, malt sprout and oat bran. There were some other faint protein bands for the crude enzyme preparations produced on brewer's spent grain, malt sprout and oat bran. The protein band between 30 and $46 \mathrm{kDa}$ was common for the enzyme preparation produced on brewer's spent grain and oat bran according to Fig. 1a. The crude enzyme preparations obtained from the fermentation of globe artichoke stem and olive seed also showed a clear protein band of approximately $20 \mathrm{kDa}$ (Fig. 1b). On the other hand, the crude enzymes obtained from the fermentation of sugar beet pulp and cotton stalk exhibited a protein band of approximately $21 \mathrm{kDa}$. A very predominate protein band between 7 and $17 \mathrm{kDa}$ was common for enzyme preparations produced on globe artichoke stem and sugar beet pulp. Very faint protein bands were obtained for cotton stalk and hazelnut skin. Summarizing, all crude enzyme preparations exhibiting xylanase activity showed a common predominant protein band of approximately 20-21 kDa, which is in accordance with the molecular masses described for A. pullulans Y-2311-1 xylanase(s) by Leathers [12]. However, it is important to emphasis that the aim was just to compare the protein profiles of the crude enzymes produced on different lignocellulosic biomass.

\section{Statistical Optimization of Xylanase Production on Wheat Bran}

In our previous study, effects of different bioprocess parameters on xylanase production by $A$. pullulans Y-2311-1 in synthetic medium were investigated by onefactor-at-a-time approach [27]. Beechwood xylan was utilized as the carbon source. Maximum enzyme production was obtained at the fourth day of the bioprocess. Yeast extract was found as the best nitrogen source for xylanase production. The optimum levels of incubation temperature, initial medium $\mathrm{pH}$ and agitation speed were found as $28{ }^{\circ} \mathrm{C}, \mathrm{pH} 3.0$ and $200 \mathrm{rpm}$, respectively. Initial medium $\mathrm{pH}$ was reported as one of the most critical factor affecting xylanase production by several fungi [19]. $\mathrm{pH}$ has profound affect on accessibility of xylanolytic enzymes to xylosidic linkages depending on the nature of the lignocellulosic biomass. Initial medium $\mathrm{pH}$ and incubation time were selected as major factors affecting xylanase production by several fungi such as Aspergillus awamori ZH-26 [28] and Penicillium oxalicum ZH-30 [29] and these factors were further optimized by RSM. Temperature has also been reported as a critical factor not only affecting the level of 


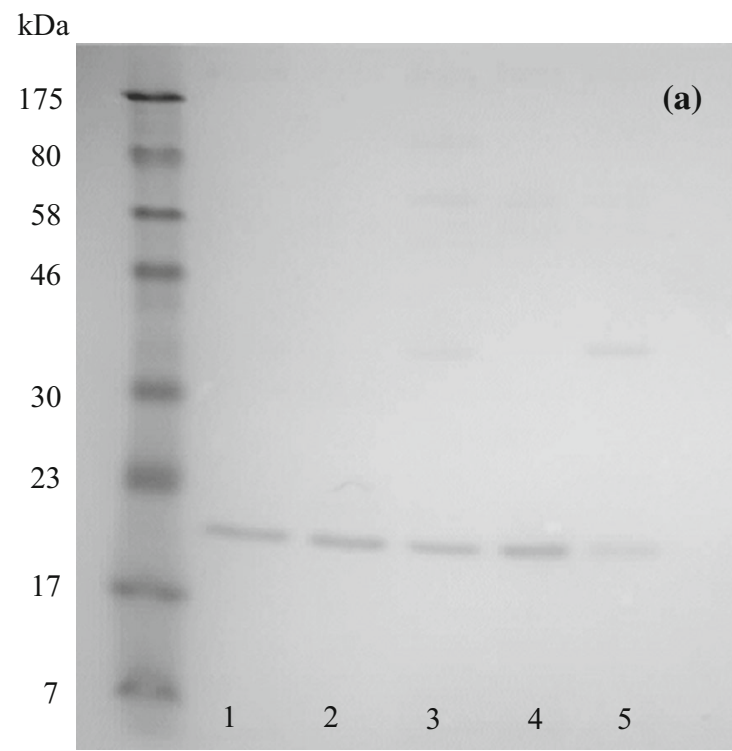

Fig. 1 SDS-PAGE profile of the crude enzymes produced on different substrates: a 1 wheat bran, 2 corn cob, 3 brewer's spent grain, 4 malt sprout, 5 oat bran and $\mathbf{b} 1$ artichoke stem, 2 sugar beet

xylanase production but also altering the biochemical properties of the enzymes [30]. Based on the earlier studies, initial medium $\mathrm{pH}\left(\mathrm{X}_{1}\right)$, temperature $\left(\mathrm{X}_{2}\right)$ and incubation time $\left(\mathrm{X}_{3}\right)$ were selected as critical parameters (Table 1a) affecting xylanase production by A. pullulans. Consequently, these variables were optimized by using RSM. The effects of these variables and their interactions on xylanase production have been determined by carrying out twenty experiments given by face centered central composite design. The responses for the 20 runs are presented in Table $1 \mathrm{~b}$. The xylanase activities obtained exhibited a wide range of variations between 13.97 and $81.13 \mathrm{U} / \mathrm{ml}$

Analysis of variance (ANOVA) for response surface quadratic model is presented in Table 3a. The accuracy of the model was manifested by $\mathrm{R}^{2}$. It was calculated as 0.99 for xylanase activity (Table 3a) indicating a very good correlation between the experimental and predicted values of the response. The adjusted coefficient of determination $\left(\operatorname{adj} \mathrm{R}^{2}\right)$ was also calculated as 0.99 which reflects the high significance of the model. Very high $\mathrm{R}^{2}(0.99)$ and adj $\mathrm{R}^{2}$ (0.99) values have also been reported for naringinase production by Aspergillus brasiliensis 1344 confirming the reliability of the defined model [31]. $\mathrm{F}$ test for regression was significant $(P<0.05)$ indicating that the model can sufficiently explain the variation observed in xylanase production with the selected levels of factors. The lack of fit test describes the failure of the model. As it is seen in Table 3a, the lack of fit $(0.165)$ was not significant $(P>0.05)$ indicating that the experimental data obtained fitted well with the model. The results clearly implied that

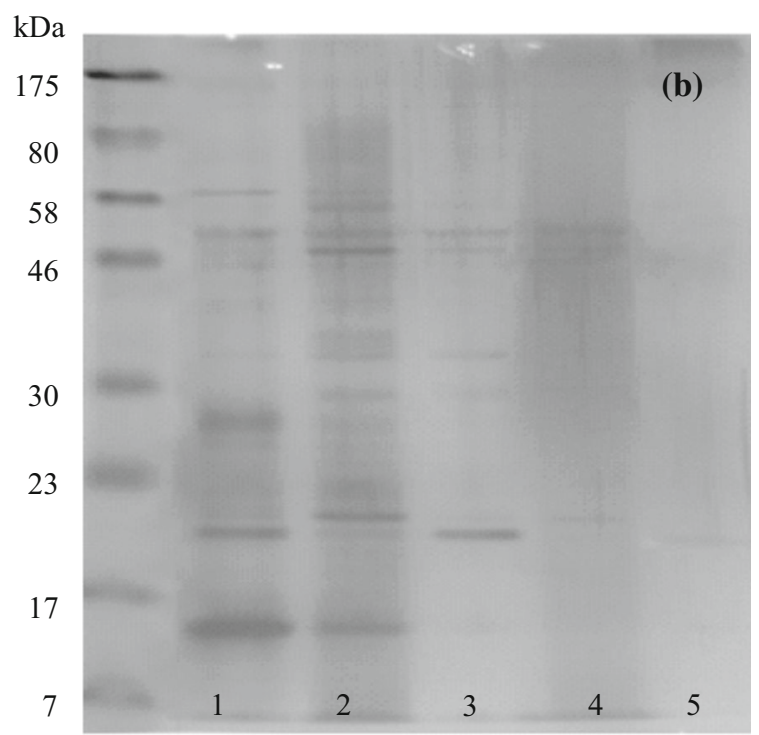

pulp, 3 olive seed, 4 cotton stalk, 5 hazelnut skin (a comassie brillant blue R250 staining; b silver staining)

the model chosen can satisfactorily explain the effect of initial medium $\mathrm{pH}$, temperature and incubation time on xylanase production by $A$. pullulans $\mathrm{Y}-2311-1$ in shake flask cultures using wheat bran as the substrate. A multiple regression analysis of the data was performed to derive an empirical model for the bioprocess in order to elucidate the relations between the response (xylanase activity) and each of the independent variables. According to the ANOVA results, the final second order polynomial equation (Eq. 3) was found to explain xylanase activity $(\mathrm{Y})$ as a function of initial medium $\mathrm{pH}\left(\mathrm{X}_{1}\right)$, temperature $\left(\mathrm{X}_{2}\right)$ and incubation time $\left(\mathrm{X}_{3}\right)$

$$
\begin{aligned}
Y= & 281.204+63.9137 X_{1}-19.1689 X_{2}-0.681180 X_{3} \\
& -7.97432 X_{1}^{2}+0.233182 X_{2}^{2}-0.00159249 X_{3}^{2} \\
& +0.121250 X_{1} X_{2}+0.0358333 X_{2} X_{3} .
\end{aligned}
$$

Regression analysis of the experimental data (Table 3b) showed that the independent variables had positive linear effect on xylanase production $(P<0.05)$. Among the three factors tested $\mathrm{pH}$ had the highest impact on xylanase activity as given by the highest linear coefficient (63.9137). While the interactions between "initial medium pH-temperature" and "temperature-incubation time" were significant $(P<0.05)$, the interaction between "initial medium pH-incubation time" was insignificant $(P>0.05)$. Therefore, this insignificant term was excluded from the final polynomial equation (Eq. 3) used for this model.

Three dimensional response surface (3D) plots were obtained by using Minitab 17 software to explore the 
Table 3 (a) ANOVA for xylanase production $\left(\mathrm{R}^{2}=0.99\right.$ and adj $\mathrm{R}^{2}=0.99$ ),

(b) estimated regression coefficients for xylanase production

\begin{tabular}{|c|c|c|c|c|c|c|}
\hline Source & $\mathrm{DF}^{\mathrm{a}}$ & Seq $S^{b}$ & Adj $S^{c}$ & Adj $\mathrm{MS}^{\mathrm{d}}$ & $\mathrm{F}$ & $P$ \\
\hline Regression & 9 & $12,305.5$ & $12,305.50$ & 1367.28 & $4 \mathrm{E}+03$ & $<0.001$ \\
\hline Linear & 3 & 7191.0 & 7190.99 & 2397.00 & $7 \mathrm{E}+03$ & $<0.001$ \\
\hline Square & 3 & 5087.6 & 5087.65 & 1695.88 & $5 E+03$ & $<0.001$ \\
\hline Interaction & 3 & 26.9 & 26.86 & 8.95 & 27.55 & $<0.001$ \\
\hline Residual error & 10 & 3.2 & 3.25 & 0.32 & & \\
\hline Lack of fit & 5 & 2.3 & 2.33 & 0.47 & 2.54 & 0.165 \\
\hline Pure error & 5 & 0.9 & 0.92 & 0.18 & & \\
\hline Total & 19 & $12,308.7$ & & & & \\
\hline
\end{tabular}

\begin{tabular}{lclrr}
\hline (b) & & & & \\
\hline Term & Coefficient & SE coefficient & \multicolumn{1}{c}{ T } & \multicolumn{1}{c}{$P$} \\
\hline Constant & 281.204 & 0.1960 & 391.262 & $<0.001$ \\
pH & 63.9137 & 0.1803 & -146.947 & $<0.001$ \\
Temperature & -19.1689 & 0.1803 & -22.906 & $<0.001$ \\
Time & -0.681180 & 0.1803 & -3.434 & 0.006 \\
pH $\times$ pH & -7.97432 & 0.3437 & -92.793 & $<0.001$ \\
Temperature $\times$ temperature & 0.233182 & 0.3437 & 2.713 & 0.022 \\
Time $\times$ time & -0.00159249 & 0.3437 & -2.668 & 0.024 \\
pH $\times$ temperature & 0.121250 & 0.2015 & 2.406 & 0.037 \\
pH $\times$ time & -0.00843750 & 0.2015 & -2.010 & 0.072 \\
Temperature $\times$ time & 0.0358333 & 0.2015 & 8.534 & $<0.001$ \\
\hline$S E$ standard error, $T$ test coefficient & & & & \\
a Degrees of freedom & & & & \\
b Sequential sum of squares & & & & \\
c Adjusted sum of squares & & & &
\end{tabular}

effects of parameters and their interactions on xylanase production. Figure $2 \mathrm{a}-\mathrm{c}$ shows the $3 \mathrm{D}$ plots of xylanase production for each pair of the factors by keeping the other factor constant at its center level. Figure 2 a depicts the effect of initial medium $\mathrm{pH}$ and temperature on xylanase production when incubation time $(96 \mathrm{~h})$ was fixed at its center level. It can be observed that the xylanase activity got increased with the increase in $\mathrm{pH}$ till its center level and beyond this point the activity got decreased dramatically. A slight decrease in enzyme activity occurred with the increase in temperature. Earlier reports on xylanase production by several fungi and bacteria have also been shown to be markedly depending on the initial medium $\mathrm{pH}$ [24]. The highest xylanase activity for Penicillium sclerotiorum was detected at $\mathrm{pH} 6.5$ for the cultures grown on oat spelt xylan [32]. It has been reported that acid $\mathrm{pH}$ values favored xylanase production by Aspergillus awamori, while $\mathrm{pH}$ values of 5.0 or higher caused a dramatic reduction in enzyme production levels [33]. The optimum $\mathrm{pH}$ for maximum activity on sorgum straw for Bacillus altitudinis DHN8 was indicated as 7.0 [34]. Generally, fungi produce xylanase at acidic $\mathrm{pH}$ while bacteria produce xylanase at higher $\mathrm{pH}$ values; however there are some exceptional cases. For example, fungi such as Aspergillus fischeri Fxn 1 and Aspergillus nidulans KK-99 were shown to produce alkaline xylanases [35]. Figure $2 b$ shows the effect of initial medium $\mathrm{pH}$ and incubation time on xylanase production when temperature $\left(28{ }^{\circ} \mathrm{C}\right)$ was fixed at its center level. It is evident that xylanase activity got increased with the increase in $\mathrm{pH}$ till its center level and beyond this point a dramatic decrease in xylanase activity occurred. There was no significant change in xylanase activity with increase in time. Similarly, Li et al. [29] also observed that there was no significant effect of incubation time on xylanase production by Penicillium oxalicum $\mathrm{ZH}$ 30 as a result of statistical optimization studies. The interaction between $\mathrm{pH}$ and incubation time was insignificant $(P>0.05)$. Additionally, the interaction coefficient between these two parameters was negative indicating that it could be assumed as negligible [36]. Figure 2c depicts 


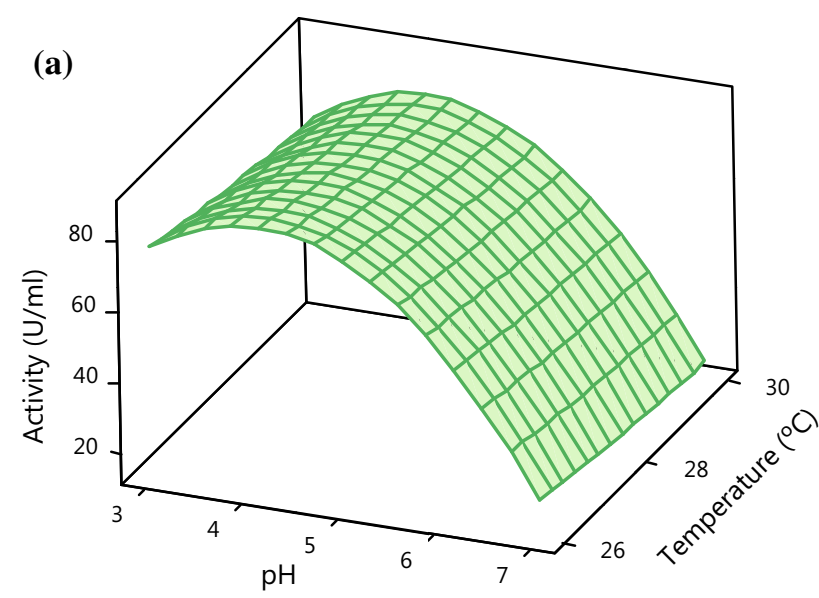

Hold value: $96 \mathrm{~h}$

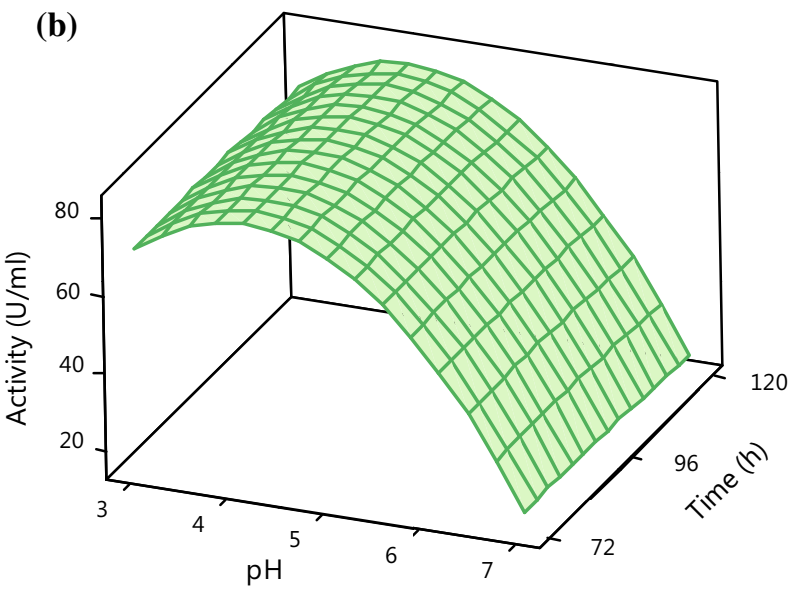

Hold value: $28^{\circ} \mathrm{C}$

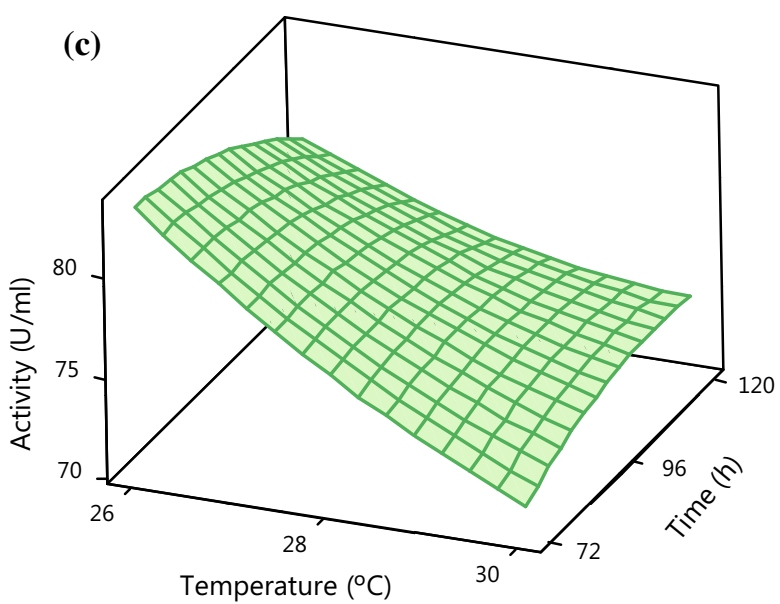

Hold value: $\mathrm{pH} 5.0$

Fig. 2 Response surface plots representing the effects of process variables on xylanase production: a effect of $\mathrm{pH}$ and temperature on xylanase production at constant time $(96 \mathrm{~h}), \mathbf{b}$ effect of $\mathrm{pH}$ and time on xylanase production at constant temperature $\left(28^{\circ} \mathrm{C}\right)$ and $\mathbf{c}$ effect of temperature and time on xylanase production at constant $\mathrm{pH}(5.0)$ the effect of temperature and incubation time on xylanase production at constant $\mathrm{pH}$ (5.0). As the temperature increased, the xylanase activity decreased. However, increment in incubation time had a slight positive impact on xylanase production.

\section{Validation of the Optimum Condition Defined by the Model}

By fitting the experimental data obtained to Eq. (3), the optimum conditions for the maximum xylanase production were determined as: initial medium $\mathrm{pH}, 4.24$; temperature, $30.27{ }^{\circ} \mathrm{C}$; and incubation time $126.67 \mathrm{~h}$. Xylanase activity was found as $85.19 \pm 2.87 \mathrm{U} / \mathrm{ml}$ experimentally under these optimum conditions. This value was in agreement with the predicted xylanase activity of $83.37 \mathrm{U} / \mathrm{ml}$ by the model. Similar experimental and predicted values reflect the accuracy and efficiency of RSM.

\section{Determination of the Effects of Agitation and Aeration on Xylanase Production in 3L Bioreactor}

For large scale xylanase production, aeration and agitation are additional important factors influencing cell growth and enzyme production. Therefore, it is important to elucidate the optimum levels of those factors in laboratory scale bioreactors at first, before going through the larger scales. Taking the RSM optimized parameters into consideration (initial medium $\mathrm{pH}, 4.24$; temperature, $30.27^{\circ} \mathrm{C}$; and incubation time $126.67 \mathrm{~h}$ ); xylanase production was carried out in 31 bioreactor with a working volume of 1.51 in order to further highlight the effect of aeration and agitation on xylanase production by $A$. pullulans. Cultivation parameters as a function of time have been evaluated at $200 \mathrm{rpm}$ agitation and $1 \mathrm{vvm}$ aeration as a starting point. The cultivation profile is shown in Fig. 3. It can be clearly observed that the peak of xylanase production was achieved after $126 \mathrm{~h}$ incubation that has previously been determined by RSM studies at shake flask level. This indicates a satisfactory representation of the bioprocess by the obtained model. Maximum enzyme production was close to $70 \mathrm{kU} / \mathrm{l}$ which could be translated into a productivity of $0.56 \mathrm{kU} / \mathrm{l} / \mathrm{h}$. Xylanase production was supported by carbohydrate and protein consumption. The $\mathrm{pH}$ of the cultivation medium slightly decreased from the initial acidic value (4.58) to 3.79 and 3.96 after incubation time of 24 and $48 \mathrm{~h}$, respectively. This could be due to the rapid consumption of easily metabolisable soluble carbohydrates that resulted in generation of acidic metabolites leading to drop in $\mathrm{pH}$ of the fermentation broth. After $48 \mathrm{~h}$ of incubation, the $\mathrm{pH}$ of the medium started to increase and reached to 5.65 at the time where the enzyme production 


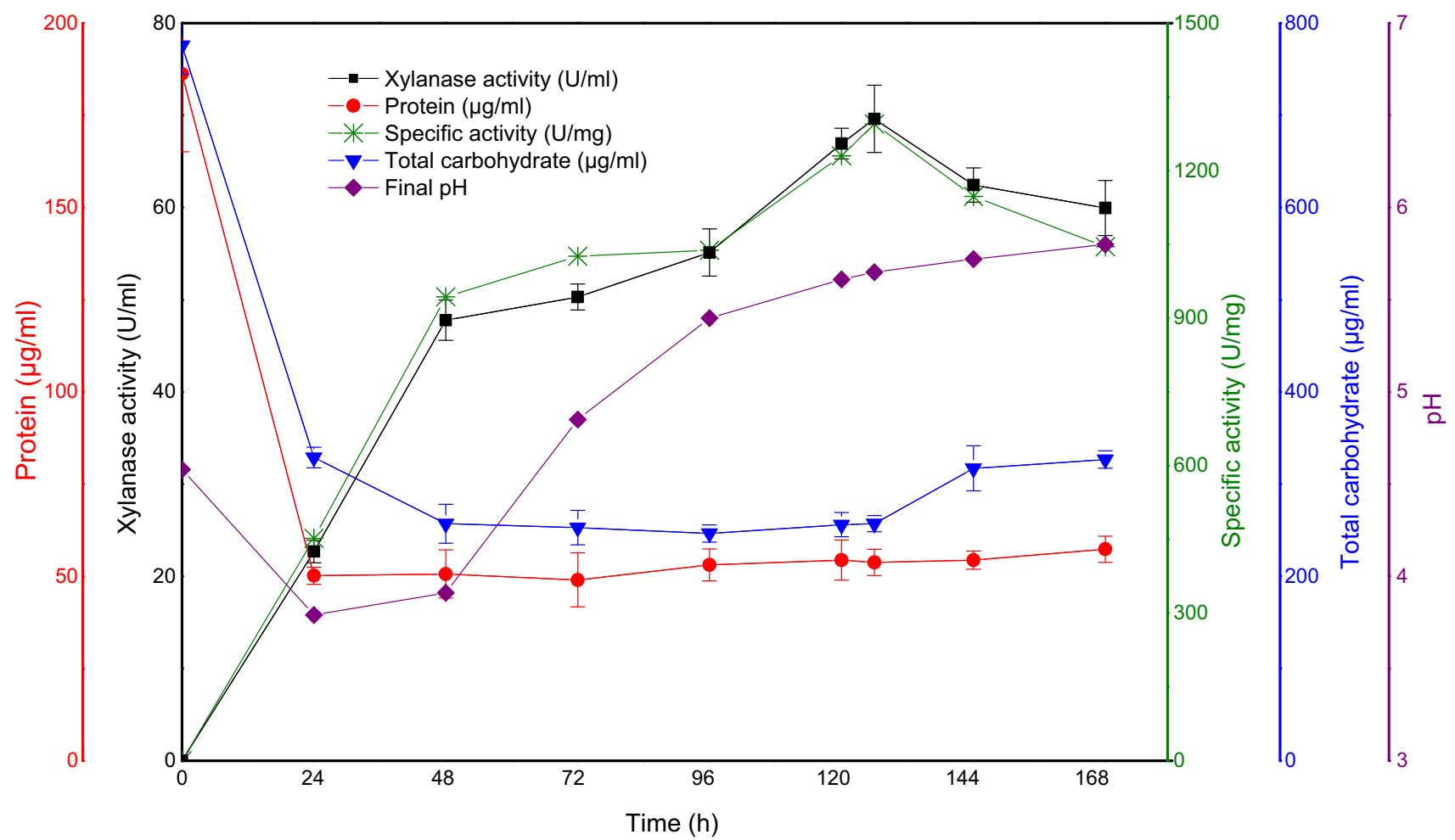

Fig. 3 Cultivation parameters alongside the time course of the fermentation process in bioreactor system (initial medium pH: 4.24; agitation: $200 \mathrm{rpm}$; aeration: $1 \mathrm{vvm}$ )

was maximum. In later phase, the increase in $\mathrm{pH}$ could be due to the consumption of acidic metabolites and cell lysis [37].

It is important to figure out the optimum aeration rate for a bioprocess. In general, very high aeration provides less holding time to the air bubbles inside the broth and creates oxygen limitation. Therefore, an increase in aeration rate beyond a certain critical limit for a particular organism can decrease the productivity of the bioprocess [38]. In the present study, four aeration $(0.5,1.0,1.5,2.0 \mathrm{vvm})$ conditions were tested in order to evaluate the effect of aeration on xylanase production. Results demonstrated that A. pullulans produced the highest xylanase activity $(85.76 \mathrm{U} / \mathrm{ml})$ when aeration was $1.5 \mathrm{vvm}$ (Table 4a). The highest specific activity $(1492.86 \mathrm{U} / \mathrm{mg})$ was also observed at $1.5 \mathrm{vvm}$. The xylanase activity decreased considerably at $2.0 \mathrm{vvm}$. Higher aeration rates also lead to foam formation which resulted in movement of significant amount of insoluble substrate (wheat bran) and cell mass with the foam. Similar observations were reported for the production of carbonyl reductase by dimorphic fungi Geotrichum candidum [37]. At this point, it is important to emphasis the difficulties of utilizing insoluble substrates since a considerable amount of wheat bran adhered to the wall of the bioreactor headspace at higher aeration rates. In order to solve the problems related with the insoluble nature of the substrate(s), Fontana et al. [39] compared the polygalacturonase activities obtained with two different culture mediums including either wheat bran or wheat bran extract. The wheat bran based medium was resulted in higher activity levels than the wheat bran extract based medium. Therefore, utilizing directly solid lignocellulosic biomass as the substrate seems to be still advantageous. However, total cost analysis of the complete bioprocesses has to be done for more precise comparison. No previous study showed the effect of aeration on xylanase production by A. pullulans. On the other hand, Cheng et al. [40] also observed that pullulan production was the highest at $1.5 \mathrm{vvm}$ by $A$. pullulans in synthetic medium and further increase in aeration rate decreased the production of pullulan.

Effect of agitation speed on xylanase production has also been evaluated by carrying out the enzyme production at three different agitation speeds $(100,200,300 \mathrm{rpm})$. The highest xylanase activity was achieved when the agitation speed was $200 \mathrm{rpm}$ (Table 4b). When agitation speed was set at $100 \mathrm{rpm}$, it was not possible to provide homogenous mixing due to the insoluble nature of the wheat bran. The xylanase production decreased when the agitation speed was increased to $300 \mathrm{rpm}$. The lower xylanase activity at higher agitation speeds can be explained by the less intimate contact between the cell mass and the wheat bran 
Table 4 (a) Effect of (a) aeration and (b) agitation speed on xylanase production

\begin{tabular}{llll}
\hline a) & & & \\
\hline Aeration $(\mathrm{vvm})$ & Xylanase activity $(\mathrm{U} / \mathrm{ml})$ & Protein $(\mu \mathrm{g} / \mathrm{ml})$ & Specific activity $(\mathrm{U} / \mathrm{mg})$ \\
\hline 0.5 & $22.19 \pm 1.48$ & $43.44 \pm 5.02$ & 510.82 \\
1.0 & $69.61 \pm 5.21$ & $55.32 \pm 2.97$ & 1258.33 \\
1.5 & $85.76 \pm 4.10$ & $57.45 \pm 3.79$ & 1492.86 \\
2.0 & $20.32 \pm 0.79$ & $51.06 \pm 3.38$ & 397.93 \\
\hline
\end{tabular}

(b)

\begin{tabular}{llll}
\hline Agitation speed $(\mathrm{rpm})$ & Xylanase activity $(\mathrm{U} / \mathrm{ml})$ & Protein $(\mu \mathrm{g} / \mathrm{ml})$ & Specific activity $(\mathrm{U} / \mathrm{mg})$ \\
\hline 100 & $35.80 \pm 2.06$ & $60.11 \pm 4.70$ & 595.61 \\
200 & $85.76 \pm 4.11$ & $57.45 \pm 3.79$ & 1492.86 \\
300 & $68.77 \pm 2.63$ & $41.13 \pm 8.06$ & 1672.02 \\
\hline
\end{tabular}

since the attachment of the cells to the wheat bran surface is reduced at higher agitation speeds [41]. On the other hand, xylanase production by filamentous fungi in submerged culture may also be affected by shear stress, which is related to the agitation rate. Mycelial damage due to high shear stress limits the use of practicable range of agitation speed values and consequently the volumetric biomass and enzyme productivity of the culture [42]. However, A. pullulans Y-2311-1 strain utilized in this study exhibited yeast like morphology under the optimized bioprocess conditions. Therefore, fungal morphology related problems were not the case in this study. This is an advantage of the A. pullulans over the other fungal strains used for xylanase production from lignocellulosic biomass.

In the present study, the yield of the xylanase production in bioreactor system $(85.76 \mathrm{U} / \mathrm{ml})$ was almost the same in comparison to that achieved in shake flask culture (85.19 U/ml). However, decreased enzyme biosynthesis in bioreactor system in comparison to shake flask cultures has been documented by other researchers [43, 44]. For example, Garai and Kumar [45] optimized the xylanase production by Aspergillus candidus on wheat bran. It has been indicated that the yield of xylanase production in bioreactor system $(47.33 \mathrm{IU} / \mathrm{ml})$ was less in comparison to that achieved in parallel shake flask culture $(69 \mathrm{IU} / \mathrm{ml})$. Kumar et al. [43] also observed that xylanase production was $40 \%$ lower in bioreactor system than in shake flask culture.

\section{Conclusion}

This study explored the potential of several agricultural byproducts for xylanase production by $A$. pullulans. Wheat bran provided maximum xylanase production. Initial medium $\mathrm{pH}$, incubation temperature and incubation time were the three important process variables for xylanase production on wheat bran. Linear, quadratic and interaction effects of these variables on xylanase production were determined using response surface methodology and the model chosen satisfactorily explained the effects of the above-mentioned process variables. Moreover, the optimized bioprocess was successfully scaled up to bioreactor system resulting in similar activity and productivity ( $85 \mathrm{kU} / \mathrm{l}$ and $0.68 \mathrm{kU} / \mathrm{l} / \mathrm{h}$ ) levels to that of shake-flask cultures. These results can constitute a basis for the scaleup of the enzyme production on agricultural wastes and byproducts to larger scales for different industrial applications.

Acknowledgments This work was financially supported by The Scientific and Technological Research Council of Turkey-TUBITAK (Project No: TOVAG 112O521) and Ege University Science and Technology Center-EBILTEM (Project No: 2013/BIL/025). S. Yegin is a management committee member in Cost Action TD1203 entitled as Food Waste Valorization for Sustainable Chemicals, Materials and Fuels (EUBis).

\section{References}

1. Collins, T., Gerday, C., Feller, G.: Xylanases, xylanase families and extremophilic xylanases. FEMS Microbiol. Rev. 29, 3-23 (2005)

2. Kulkarni, N., Shendye, A., Rao, M.: Molecular and biotechnological aspects of xylanases. FEMS Microbiol. Rev. 23, 411-456 (1999)

3. Elgharbi, F., Hmida-Sayari, A., Zaafouri, Y., Bejar, S.: Expression of an Aspergillus niger xylanase in yeast: application in breadmaking and in vitro digestion. Int. J. Biol. Macromol. 79, 103-109 (2015)

4. Beg, Q.K., Kapoor, M., Mahajan, L., Hoondal, G.S.: Microbial xylanases and their industrial applications: a review. Appl. Microbiol. Biotechnol. 56, 326-338 (2001)

5. Wong, K.K.Y., Saddler, J.N.: Trichoderma xylanases, their properties and purification. Crit. Rev. Biotechnol. 12, 413-435 (1992)

6. Wang, X., Luo, H., Yu, W., Ma, R., You, S., Liu, W., Hou, L., Zheng, F., Xie, X., Yao, B.: A thermostable Gloeophyllum 
trabeum xylanase with potential for the brewing industry. Food Chem. 99, 516-523 (2016)

7. Dobrev, G.T., Pishtiyski, I.G., Stanchev, V.S., Mircheva, R.: Optimization of nutrient medium containing agricultural wastes for xylanase production by Aspergillus niger B03 using optimal composite experimental design. Bioresour. Technol. 98, 2671-2678 (2007)

8. Joo, H.S., Chang, C.S.: Production of protease from a new alkalophilic Bacillus sp. I-312 grown on soybean meal: optimization and some properties. Process Biochem. 40, 1263-1270 (2005)

9. Katapodis, P., Christakopoulou, V., Kekos, D., Christakopoulos, P.: Optimization of xylanase production by Chaetomium thermophilum in wheat straw using response surface methodology. Biochem. Eng. J. 35, 136-141 (2007)

10. Bakir, U., Yavascaoglu, S., Guvenc, F., Ersayin, A.: An endo- $\beta$ 1,4-xylanase from Rhizopus oryzae: production, partial purification and biochemical characterization. Enzyme Microb. Technol. 29, 328-334 (2001)

11. Kar, S., Gauri, S.S., Das, A., Jana, A., Maity, C., Mandal, A., Mohapatra, P.K.D., Pati, B.R., Mondal, K.C.: Process optimization of xylanase production using cheap solid substrate by Trichoderma reesei SAF3 and study on the alteration of behavioral properties of enzyme obtained from SSF and SmF. Bioprocess Biosyst. Eng. 36, 57-68 (2013)

12. Leathers, T.D.: Colour variants of Aureobasidium pullulans overproduce xylanase with extremely high specific activity. Appl. Environ. Microbiol. 52, 1026-1030 (1986)

13. Christov, L.P., Myburgh, J., Van Tonder, A., Prior, B.A.: Hydrolysis of extracted and fiber bound xylan with Aureobasidium pullulans enzymes. J. Biotechnol. 55, 21-29 (1997)

14. Silbir, S., Dagbagli, S., Yegin, S., Baysal, T., Goksungur, Y.: Levan production by Zymomonas mobilis in batch and continuous fermentation systems. Carbohdr. Polym. 99, 454-461 (2014)

15. Bailey, M.J., Bieley, P., Poutanen, K.: Interlabratory testing of methods for assay of xylanase activity. J. Biotechnol. 23, 257-270 (1992)

16. Dubois, M., Gilles, K.A., Hamilton, J.K., Rebers, P.A., Smith, F.: Colorimetric method for determination of sugars and related substances. Anal. Chem. 29, 350-356 (1956)

17. Laemmli, U.K.: Cleavage of structure proteins during the assembly of the head of bacteriophage T4. Nature 227, 680-685 (1970)

18. Heukeshoven, J., Dernick, R.: Simplified method for silver staining of proteins in polyacrylamide gels and the mechanism of silver staining. Electrophoresis 6, 103-112 (1985)

19. Haltrich, D., Nidetzky, B., Kulbe, K.D., Steiner, W., Silvia Zupancic, S.: Production of fungal xylanase. Bioresour. Technol. 58, 137-161 (1996)

20. Polizeli, M.L.T.M., Rizzatti, A.C.S., Monti, R., Terenzi, H.F., Jorge, J.A., Amorim, D.S.: Xylanases from fungi: properties and industrial applications. Appl. Microbiol. Biotechnol. 67, 577-591 (2005)

21. Li, K., Azadi, P., Collins, R., Tolan, J., Kim, J.S., Eriksson, K.E.L.: Relationships between activities of xylanases and xylan structures. Enzyme Microb. Technol. 27, 89-94 (2000)

22. Scheller, H.V., Ulvskov, P.: Hemicelluloses. Annu. Rev. Plant Biol. 61, 263-289 (2010)

23. Merali, Z., Collins, S.R.A., Elliston, A., Wilson, D.R., Käsper, A., Waldro, K.W.: Characterization of cell wall components of wheat bran following hydrothermal pretreatment and fractionation. Biotechnol. Biofuels 8, 23 (2015). doi:10.1186/s13068-0150207-1

24. Kumar, A., Gupta, R., Shrivastava, B., Khasa, Y.P., Kuhad, R.C.: Xylanase production from an alkalophilic actinomycete isolate Streptomyces sp. RCK-2010, its characterization and application in saccharification of second generation biomass. J. Mol. Cat. B Enzym. 74, 170-177 (2012)

25. Cui, Y.Q., Ouwehand, J.N.W., van der Lans, R.G.J.M., Giuseppin, M.L.F., Luyben, K.C.A.M.: Aspects of the use of complex media for submerged fermentation of Aspergillus awamori. Enzyme Microb. Technol. 23, 168-177 (1998)

26. Demir, H., Tari, C.: Valorization of wheat bran for the production of polygalacturonase in SSF of Aspergillus sojae. Ind. Crops Prod. 54, 302-309 (2014)

27. Yegin, S.: Determination of the bioprocess parameters effecting xylanase production by Aureobasidium pullulans. Gida (2017). doi:10.15237/gida.GD16053

28. Li, Y., Lin, J., Meng, D., Lu, J., Gu, G., Mao, Z.: Effect of pH, cultivation time and substrate concentration on the endoxylanase production by Aspergillus awamori $\mathrm{ZH}-26$ under submerged fermentation using central composite rotary design. Food Technol. Biotechnol. 44, 473-477 (2006)

29. Li, Y., Cui, F., Liu, Z., Xu, Y., Zhao, H.: Improvement of xylanase production by Penicillium oxalicum ZH-30 using response surface methodology. Enzyme Microb. Technol. 40, 1381-1388 (2007)

30. Fang, H.Y., Chang, S.M., Hsieh, M.C., Fang, T.J.: Production, optimization growth conditions and properties of the xylanase from Aspergillus carneus M34. J. Mol. Catal. B Enzym. 49, 36-42 (2007)

31. Shanmugaprakash, M., Kirthika, J., Ragupathy, J., Nilanee, K., Manickam, A.: Statistical based media optimization and production of naringinase using Aspergillus brasiliensis 1344. Int. J. Biol. Macromol. 64, 443-452 (2014)

32. Knob, A., Carmona, E.C.: Xylanase production by Penicillium sclerotiorum and its characterization. World Appl. Sci. J. 4, 277-283 (2008)

33. Smith, D.C., Wood, T.M.: Xylanase production by Aspergillus awamori. Development of a medium and optimization of the fermentation parameters for the production of extracellular xylanase and $\beta$-xylosidase while maintaining low protease production. Biotechnol. Bioeng. 38, 883-890 (1991)

34. Adhyaru, D.N., Bhatt, N.S., Modi, H.A.: Enhanced production of cellulase-free, thermo-alkali-solvent-stable xylanase from Bacillus altitudinis DHN8, its characterization and application in sorghum straw saccharification. Biocatal. Agric. Biotechnol. 3, 182-190 (2014)

35. Nagar, S., Mittal, A., Kumar, D., Gupta, V.K.: Production of alkali tolerant cellulase free xylanase in high levels by Bacillus pumilus SV-205. Int. J. Biol. Macromol. 50, 414-420 (2012)

36. Singh, R., Kumar, R., Bishnoi, K., Bishnoi, N.R.: Optimization of synergistic parameters for thermostable cellulase activity of Aspergillus heteromorphus using response surface methodology. Biochem. Eng. J. 48, 28-35 (2009)

37. Bhattacharyya, M.S., Singh, A., Banerjee, U.C.: Production of carbonyl reductase by Geotrichum candidum in a laboratory scale bioreactor. Bioresour. Technol. 99, 8765-8770 (2008)

38. Biswas, R., Sahai, V., Mishra, S., Bisaria, V.S.: Bioprocess strategies for enhanced production of xylanase by Melanocarpus albomyces IITD3A on agro-residual extract. J. Biosci. Bioeng. 110(6), 702-708 (2010)

39. Fontana, R.C., Polidoro, T.A., Silveira, M.M.: Comparison of stirred tank and airlift bioreactors in the production of polygalacturonases by Aspergillus oryzae. Bioresour. Technol. 100, 4493-4498 (2009)

40. Cheng, K.C., Demirci, A., Catchmark, J.M.: Evaluation of medium composition and fermentation parameters on pullulan production by Aureobasidium pullulans. Food Sci. Technol. Int. 17(2), 99-109 (2011)

41. Michelin, M., Polizeli, M.L.T.M., Silva, D.P., Ruzene, D.S., Vicente, A.A., Jorge, J.A., Terenzi, H.F., Teixeira, J.A.: 
Production of xylanolytic enzymes by Aspergillus terricola in stirred tank and airlift tower loop bioreactors. J. Ind. Microbiol. Biotechnol. 38, 1979-1984 (2011)

42. Chipeta, Z.A., Du Preez, J.C., Christopher, L.: Effect of cultivation $\mathrm{pH}$ and agitation rate on growth and xylanase production by Aspergillus oryzae in spent sulphite liquor. J. Ind. Microbiol. Biotechnol. 35, 587-594 (2008)

43. Kumar, K.S., Manimaran, A., Permaul, K., Singh, S.: Production of $\beta$ - xylanase by a Thermomyces lanuginosus MC134 mutant on corn cobs and its application in biobleaching of bagasse pulp. J. Biosci. Bioeng. 107, 494-498 (2009)
44. Gomes, D.J., Gomes, J., Steiner, W.: Production of highly thermostable xylanase by a wild strain of thermophilic fungus Thermoascus aurantiacus and partial characterization of the enzyme. J. Biotechnol. 37, 11-22 (1994)

45. Garai, D., Kumar, V.: Response surface optimization for xylanase with high volumetric productivity by indigenous alkali tolerant Aspergillus candidus under submerged cultivation. 3 Biotech. 3, 127-136 (2013) 